\title{
CONCEPTION OF A WATER LEVEL DETECTOR (TIDE-GAUGE) BASED ON A ELECTROMAGNETIC SENSOR OF FORCE
}

\author{
Zakaryae.Ezzouine ${ }^{1}$, Abdelrhani.Nakheli ${ }^{2}$ \\ ${ }^{I}$ LASMAR, Faculty of Sciences, Moulay Ismail University, Meknes, Morocco \\ ${ }^{2}$ Electrical Engineering Departments, ESTM, Moulay Ismail University, Meknes, Morocco
}

\begin{abstract}
The mechanism that we propose is a water level sensor (Tide-Gauge), using the Archimedes principle, according to which a body immersed in a fluid in equilibrium, subjected to on behalf of this one a thrust which the intensity is equal to the weight of the fluid displaced. It is composed of an electromagnetic sensor forces of which is suspended a plunger cylindrical glass. The latter is partially introduced into a measuring cylinder filled with water. The electromagnetic sensor of forces allows us to measure the difference between the weight of the cylinder and the force due to the buoyancy exerted by the water on the submerged part of the cylinder. When the water level in the test piece changes it is implied by a variation of the submerged portion of the cylinder, and causes a variation of the buoyancy, as a consequence of variation of the force exerted on the sensor. The electromagnetic sensor allows the conversion of this force into a voltage by the intermediate of an electronic circuit.
\end{abstract}

Key Words: Electromagnetic Sensor of Force, Water Level Detector, Tide-Gauge.

$* * *$

\section{INTRODUCTION}

Knowing the sea level is an important information; it give us an idea about global warming, the dilation of the oceans, melting of glaciers, and allows tsunami prediction [1 - 4]. In the observatories of tide, several types of tide gauges and measurement techniques are used, tide scale, probe light, tide to float, tide gauges to pressure sensors, tide ultrasonic or electromagnetic waves microwave (radar),...etc [5]. The tide that we propose relies on the laws of mechanics of fluids, of the mechanical, and the fundamental laws of electromagnetism.

This is a new conception that presents the advantages of a simple structure, low cost and an acceptable precision of observation.

\section{PRINCIPALE OPERATION OF FUNCTION} \section{TIDE GAUGE}

project is concerned an instrument of measuring water level (Tide-gauge), using Archimedes principle, according to which once a body immersed in a fluid in a state of equilibrium, it become subjected to a thrust which the intensity of which is equal to the weight of the displaced fluid. It is composed of an electromagnetic sensor of forces from which is a glass plunger cylindrical is suspended; the latter is partially introduced into a measuring cylinder filled with water. The electromagnetic sensor of forces allows you to measure the difference between the weight of the cylinder and the force emanating from the buoyancy exerted by the water on the submerged part of the cylinder.

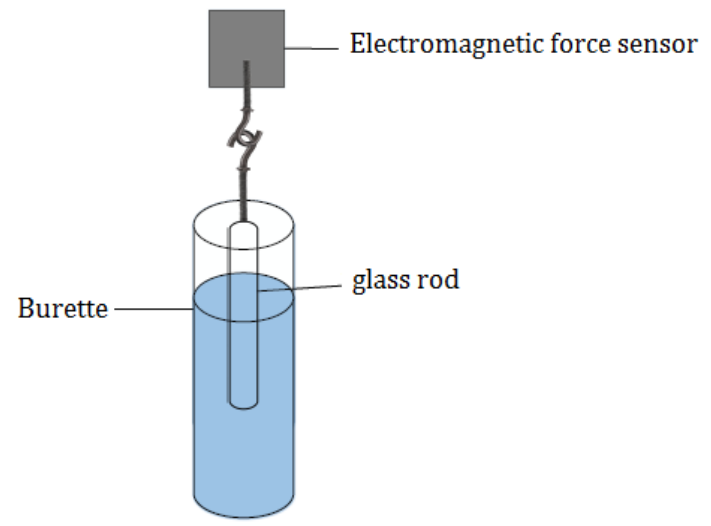

Fig -1: Diagram of the function operation of the Tide Gauge

When the water level in the test piece varies; this is reflected by a variation of the submerged portion of the cylinder, and causes a variation of the buoyancy, or a variation of the force exerted on the sensor. The electromagnetic sensor allows the conversion of this force into a voltage, by the intermediate of an electronic circuit [6-7].

\section{DESCRIPTION OF THE EXPERIMENTAL DEVICE}

The experimental device that we propose for the measurement of the level of water is composed, of a sensor of electromagnetic forces from which is suspended a plunger cylindrical glass which is partially introduced into a graduated cylinder, and a system for filling and draining the water in the measuring cylinder Fig -2. This system allows us to adjust the water level to heights well determined in the graduated cylinder, and as a result allows you variate the 
portion of the cylinder immersed in water. The contribution of the electrical energy to the sensor of forces, is assured by a stabilized power supply \pm 15 . The output of the sensor is connected to a circuit of packaging, through the connecting wires, the circuit output of packaging of the sensor is connected to a voltmeter of table to digital display that allows the reading of the voltage.

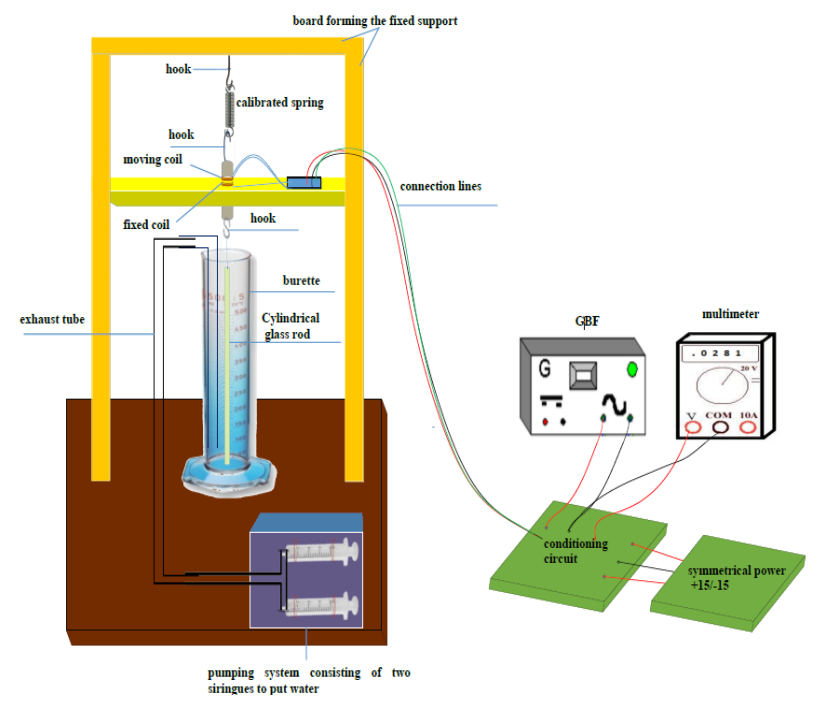

Fig -2: Diagram of the device for measuring water level by an electromagnetic sensor of forces.

\section{OPERATING PRINCIPALE OF THE SENSOR FOR ELECTROMAGNETIC FORCES}

The sensor of forces that we propose consists of a spring $\boldsymbol{R}$, two flat coils of 30 coils each, and of $2 \mathrm{~cm}$ radius, a flat coil is mounted on a support around a hole (transmitting coil), it is supplied by a sinusoidal signal from a Low Frequency Generator. The second coil receiving platform $\mathrm{BM}$ is wound on an insulating cylinder of $2 \mathrm{~cm}$ radius and $5.3 \mathrm{~cm}$ height, The latter is suspended by a hook at the lower end of a spring whose upper end is fixed on a support through a hook Fig -3.

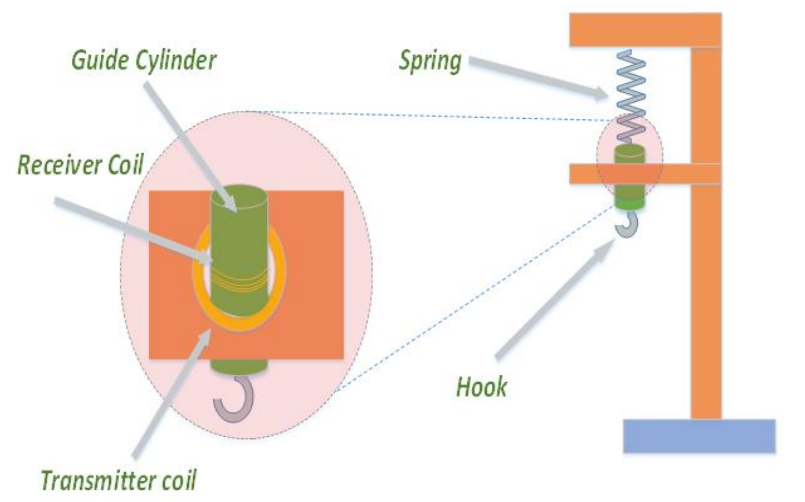

Fig -3: The sensor for electromagnetic forces

The spring assembly, cylinder and port are well aligned vertically in a manner that the cylinder passes through the hole virtually without friction. The two receiving coils and issuing are linked to the conditioning circuit through the wires of connections. A hook is fixed on the lower part of the cylinder and is used to suspend the masses. The two coils are still parallel, remote $\mathrm{X}$ one of the other, $\mathrm{X}$ being the variable distance between coils.

The power supply to the fixed coil by issuing from the sinusoidal voltage of a given frequency and an amplitude of a given outcome of the Low Frequency Generator, produces a sinusoidal current in the latter and creates a magnetic induction variable along its axis. The coil receiving mobile is the headquarters of an electromotive induced force variable and measurable [8-9]:

$$
e=-\frac{d \Phi}{d t}
$$

The maximum value of this Electrometric Force induced depends on the distance $\mathrm{x}$ between the two coils, and the flux $\Phi$ is proportional to the magnetic induction B, whose variation, as a function of $\mathrm{x}$, is given by the following relationship :

$$
B(x)=\frac{\mu_{0} * N^{*} I^{*} R^{2}}{2 *\left(R^{2}+X^{2}\right)^{3 / 2}}
$$

With I the current flowing through the coils, $\mathrm{R}$ their radius, $\mathrm{N}$ their number of spire, and $\mathrm{x}$ the distance between the two coils. For $\mathrm{x}=0$, the previous formula becomes simple, and thus:

$$
B(0)=\frac{\mu_{0} * N * I}{2 R}
$$

\section{CHARACTERISTICS AND PERFORMANCES ELECTROMAGNETIC FORCE SENSOR}

The proposed sensor is characterized by a drift (original): When one puts the sensor in function, there is a slow drift, and after approximately 2 hours of operation, this drift is canceled, and the voltage output of the sensor is stabilized at a constant.

The sensor response, V (m), is not linear, but it obeys to a polynomial relationship. The immediate consequence of this non-linearity is a variable sensitivity, which involves the distance $\mathrm{x}$ between the two coils. The accuracy of this sensor depends, obviously, on the specific elements of the experimental device (coils, friction, distance inter coil, number of coils, spring, and circuit of signal conditioning), and the quality of the measuring device used.

\subsection{Determination of the mechanical characteristic of the spring $K$}

The curve of the Determination of the mechanical characteristic of the spring $\mathrm{K}$ is obtained by hooking the masses of precision ranging from $0 \mathrm{~g}$ to $30 \mathrm{~g}$ by steps of $5 \mathrm{~g}$ and by reading the displacement $\mathrm{X}$ of corresponding spring, using a graduated ruler as scale, (Table. 1 above): 
Table -1 : Table of the characteristic of the spring

\begin{tabular}{|c|c|}
\hline $\mathrm{M}(\mathrm{g})$ & $\mathrm{X}(\mathrm{mm})$ \\
\hline 0 & 0 \\
\hline 5 & 0.75 \\
\hline 10 & 1.5 \\
\hline 15 & 2.25 \\
\hline 20 & 3 \\
\hline 25 & 3.75 \\
\hline 30 & 4.5 \\
\hline
\end{tabular}

M: The Weight

$\mathbf{X}$ : The displacement of the spring by

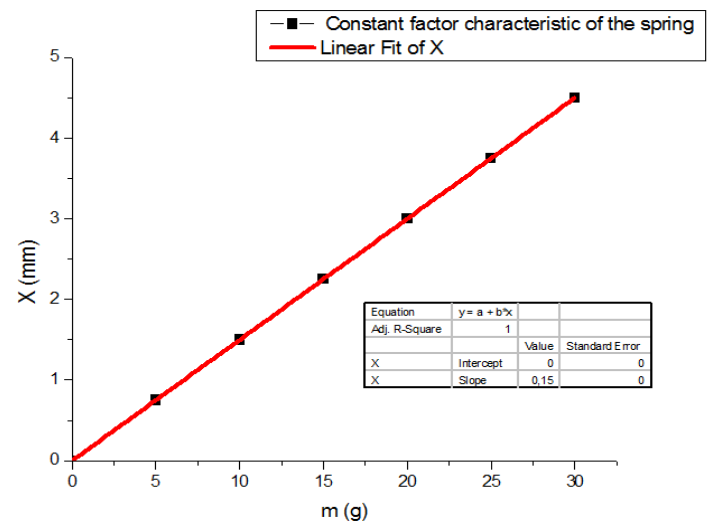

Chart -1: The mechanical characteristic of the spring K.

From the curve:

$$
\begin{gathered}
K=\frac{\Delta M}{\Delta X} \\
K=\frac{5 g}{0.75 \mathrm{~mm}}=6.667 \mathrm{~N} / \mathrm{m}
\end{gathered}
$$

\subsection{Calibration the Sensor of forces}

The characteristic curve of the sensor, $V=f(m)$, is obtained by hooking the masses of precision ranging from $0 \mathrm{~g}$ to $30 \mathrm{~g}$ by steps of $2.5 \mathrm{~g}$ (table. 1 above), and by raising the corresponding voltage, using a voltmeter with a precision $0.1 \mathrm{mV}$.

Table -2: The calibration curve of the sensor of electromagnetic forces.

\begin{tabular}{|c|c|}
\hline $\mathrm{M}(\mathrm{g})$ & $\mathrm{V}(\mathrm{mv})$ \\
\hline 0 & 49.5 \\
\hline 2.5 & 51.9 \\
\hline 5 & 54.6 \\
\hline 7.5 & 57.9 \\
\hline 10 & 61.5 \\
\hline 12.5 & 66.0 \\
\hline 15 & 71.1 \\
\hline 17.5 & 77.1 \\
\hline 20 & 83.5 \\
\hline 22.5 & 91.8 \\
\hline 25 & 101.1 \\
\hline 27.5 & 111.7 \\
\hline 30 & 122.6 \\
\hline
\end{tabular}

Where $\mathbf{M}$ is the Weight and $\mathbf{V}$ is The Voltage.

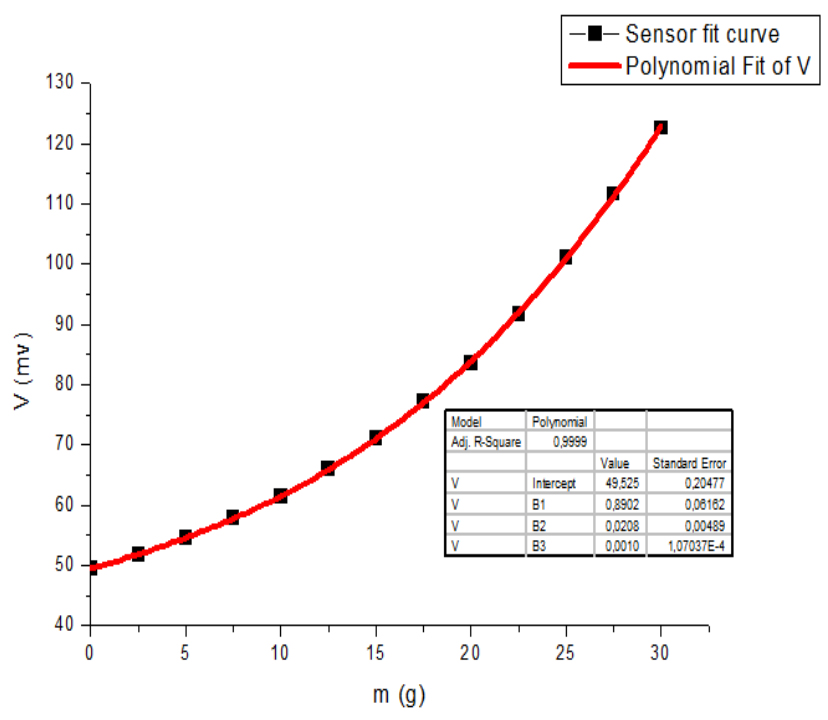

Chart -2: Sensor response $V=f(m)$

We used a polynomial fit of order 5 which is characterized by a standard deviation commensurate with the experimental sensor accuracy. The polynomial fit of the mass as a function of the voltage $(m=f(V))$ shown below will be most useful for determining the mass of any unknown by knowing its corresponding voltage delivered by the sensor. The corresponding polynomial adjustment is given by:

$$
m=\sum_{i=0}^{5} a v_{i}^{i}
$$

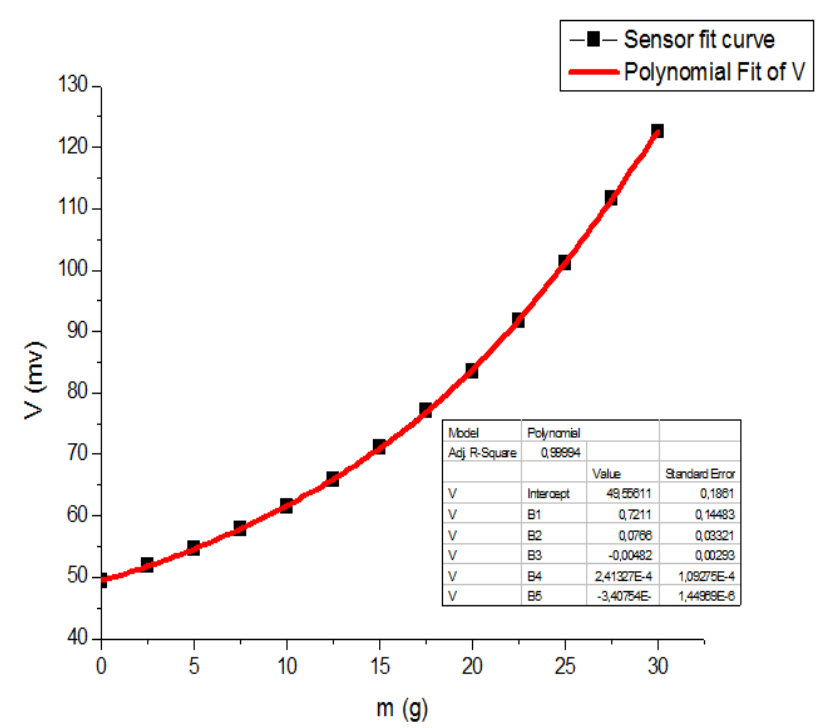

Chart -3: The calibration curve of the sensor of electromagnetic forces

The polynomial adjustment of the mass as a function of the voltage corresponding to the experimental accuracy of our sensor is as follows:

$$
\mathrm{m}(\mathrm{g})=\mathrm{A}+\mathrm{B}_{1} \mathrm{~V}+\mathrm{B}_{2} \mathrm{~V}^{2}+\mathrm{B}_{3} \mathrm{~V}^{3}+\mathrm{B}_{4} \mathrm{~V}^{4}+\mathrm{B}_{5} \mathrm{~V}^{5}
$$


With:

$A=49,55611 ; B_{1}=0,7211 ; B_{2}=0,0766$;

$B_{3}=-0,00482 ; B_{4}=2,41327 \mathrm{E}-4 ; B_{5}=-3,40754$ E-6

$r^{2}=1$ and $\sigma=0,25513$

$B_{i}$ : Coefficients of the characteristic polynomial.

$r^{2}$ : Correlation coefficient.

$\sigma$ : Residual sum of squares.

The electromagnetic sensor of forces proposed is characterized by its extended of measure $0 \mathrm{~g}$ to $30 \mathrm{~g}$, which depends on the mechanical characteristics of the spring. A cycle of hysteresis appears when exceeding a certain critical elongation, and there is emergence of a deformation retentive. The choice of a good spring perfectly elastic is important. The range of use of the sensor is limited between $0 \mathrm{~g}$ and $30 \mathrm{~g}$ in which all measures are reversible. The sensitivity of the sensor offers depends on the distance $\mathrm{x}$ inter-coils, but it is almost invariable and of fixed distance.

The accuracy of the sensor depends on the specific elements of the experimental device (coils, friction, distance inter coil, number of coils, spring, and circuit of signal conditioning [10]), and the quality of the measuring device used. We have used a digital voltmeter of a precision of 0.1 $\mathrm{mV}$.

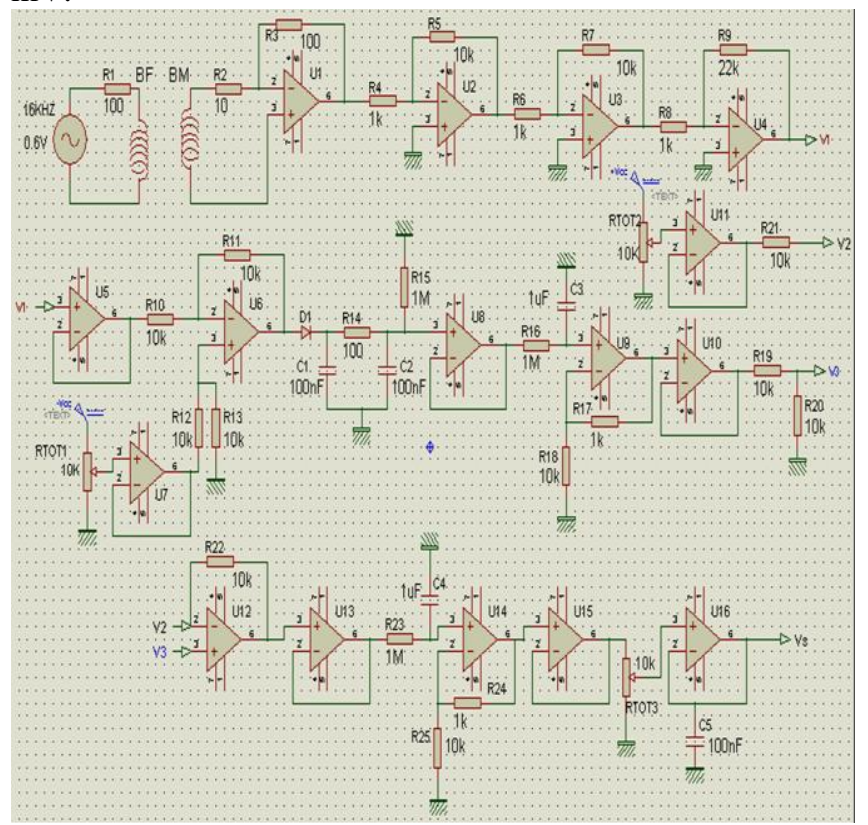

Fig -4: Conditioning circuit

\section{EXPERIMENTAL TECHNIQUES USED}

\subsection{Principle of measurement}

We denote by $\rho_{L}$, the density of water expressed in $\mathrm{g} / \mathrm{cm} 3$, $M_{S}$ the mass of the plunger cylindrical in (grams), $\rho_{S}$ his density $\left(\rho_{S} \succ \rho_{L}\right), V$ it's immersed volume in (cm 3) which is also equal to the volume of the fluid displaced, $g$ the intensity of the gravity field [11-12-13].
The intensity $P_{A}$ of the thrust of Archimedes and the force $F$ applied to the sensor are data by:

$$
P_{A}=\rho_{L} * V * g
$$

And

$$
F=M_{S} * g-P_{A},
$$

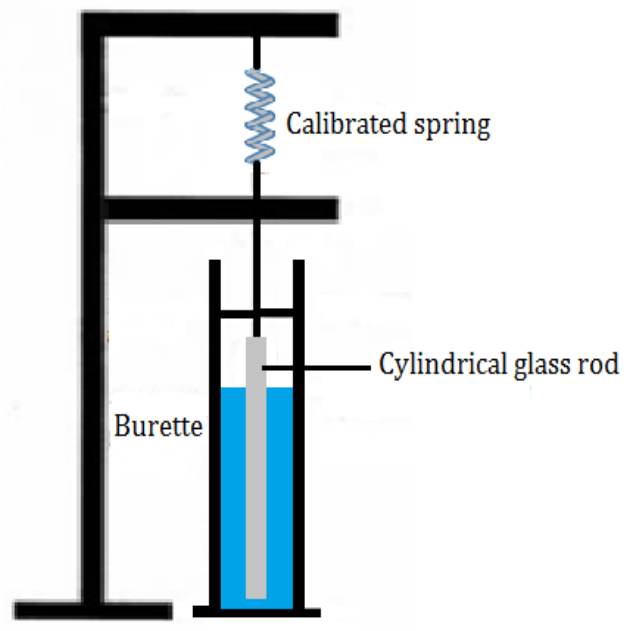

Fig -5: Diagram for the measurement principle

The measurement of $F$ gives directly the value of volume $V$ cylinder partially immersed in the water:

$$
V=S * h
$$

The section $S$ of the cylinder being constant, it can be deduced that $h$ represents the height of the submerged portion of the cylinder, and therefore the level of water in the measuring cylinder.

The force $\mathrm{F}$ is measured using the electromagnetic sensor of forces whose the extended measurement is $30 \mathrm{~g}$, and which was calibrated by using weights of accuracy and the results of which are presented on the table with the calibration curve Chart -3.

\subsection{Measures and Experimental Results}

Our experimental device is equipped with a mechanism of filling and draining of the graduated measuring cylinder. We have begun by the filling of the test piece up to a maximum level, and we proceeded to the decrease of the level by constant step of $1 \mathrm{~cm}$, the water level in passing by different heights. And at each height, we have raised the voltage delivered by the sensor of electromagnetic forces using a voltmeter. We have achieved the reverse operation also by completing the test piece gradually by step of $1 \mathrm{~cm}$; the results of measures during the lowering and raising of the waters are cited below.

\subsection{Measurement of the rise in water level}

Table of measures of the output voltage of Tide Gauge Data and the level of water 
Table -4: Measurement table of water rising

\begin{tabular}{|c|c|}
\hline Water level in $(\mathrm{Cm})$ & Voltage in $(\mathrm{mv})$ \\
\hline 0 & 44,5 \\
\hline 1 & 45,3 \\
\hline 2 & 46,4 \\
\hline 3 & 48,5 \\
\hline 4 & 50,6 \\
\hline 5 & 53,6 \\
\hline 6 & 57,2 \\
\hline 7 & 63,7 \\
\hline 8 & 71,4 \\
\hline 9 & 81,4 \\
\hline 10 & 89,7 \\
\hline 11 & 99,2 \\
\hline 12 & 107,5 \\
\hline 13 & 116,9 \\
\hline
\end{tabular}

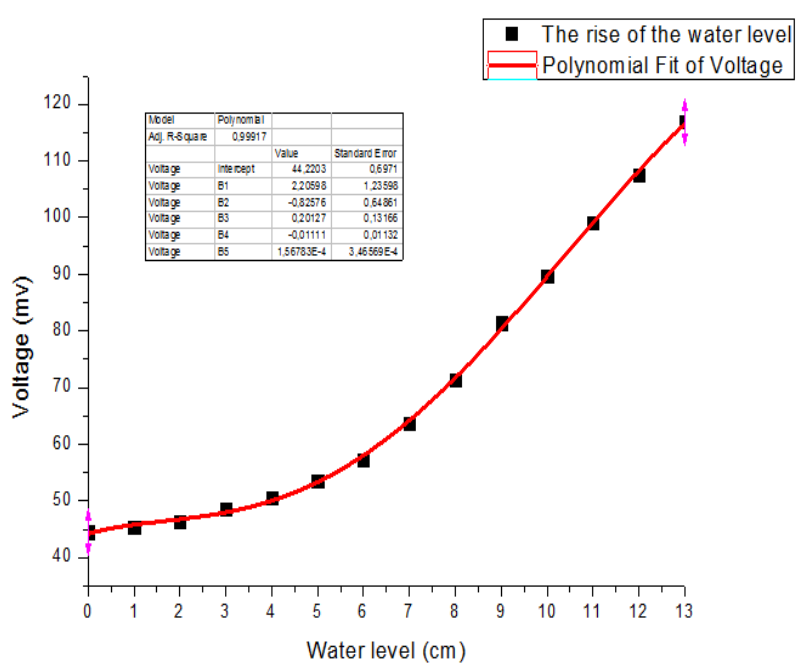

Chart -5: Graph of the rise in water level

\subsection{Measurement of the decrease of water level}

Table of measures of the output voltage of Tide Gauge Data and the level of water:

Table -3: Measurement table of water descent

\begin{tabular}{|c|c|}
\hline Water level in $(\mathrm{Cm})$ & Voltage in $(\mathrm{mv})$ \\
\hline 13 & 116,9 \\
\hline 12 & 107,5 \\
\hline 11 & 99,2 \\
\hline 10 & 89,7 \\
\hline 9 & 81,4 \\
\hline 8 & 71,4 \\
\hline 7 & 63,7 \\
\hline 6 & 57,2 \\
\hline 5 & 53,6 \\
\hline 4 & 50,6 \\
\hline 3 & 48,5 \\
\hline 2 & 46,4 \\
\hline 1 & 45,3 \\
\hline 0 & 44,5 \\
\hline
\end{tabular}

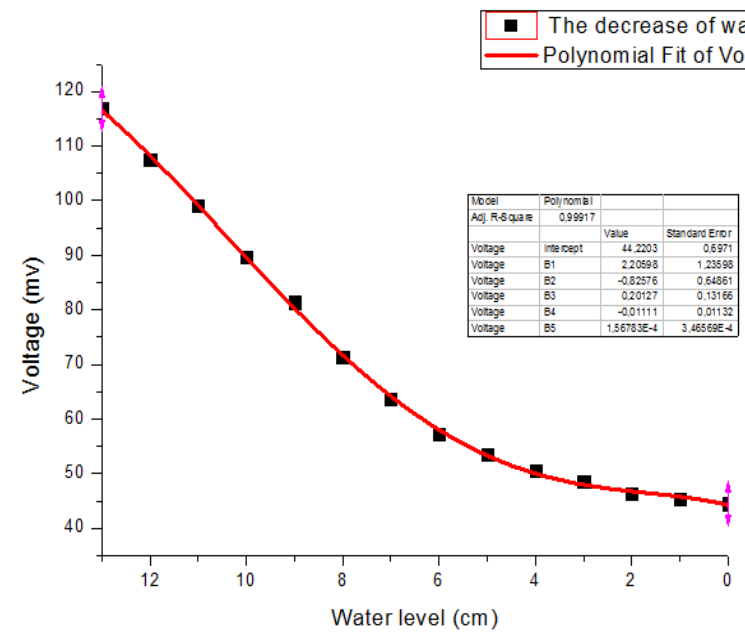

Chart -4: Graph of the descent in water level

The Comparison between graphical representation of the rising and lowering of waters, shows that the variations are reversible and that at each level of water corresponds to a voltage .

\section{CONCLUSIONS}

We have come up with a device to measure the level of water in a measuring cylinder using an electromagnetic sensor of forces to which we have attacked a cylindrical plunger. The reading of tensions in function of the water level shows that the variations are monotonous. These results obtained in the laboratory are derived from measurements made in almost-ideal conditions, in which the fluid is in hydrostatic balance, and the application of the principle of static fluids is verified. During the operation of the level sensor in the waters of sea, we can expect a behavior that sets itself of the ideal operation because of the hydrostatic balance of sea water which is not always achieved since there are some spills during the blast high and low. To approach the operation observed at the laboratory, the installation of the tide gauge data must be protected from waves, and predict a construction to stabilize the waters in order to consider a quasi hydrostatic equilibrium. By taking into consideration certain precautions, the mechanism that we propose can serve as an instrument for measuring water level (Tide-Gauge) that is robust and reliable for the knowledge of the variations of the average level of the sea which represents an important contribution to the understanding of climate change, and to follow the time evolution of the rise and descent of sea water with precision.

Improvements can be made to this device to increase its performance, by associating an acquisition card for a digital data processing by computer, as well as the transmission of the results in real time.

\section{REFERENCES}

[1]. N. Pouvreau, Thèse de Doctorat de L’Univérsité de la ROCHELLE, géophysique «Trois cents ans de mesures marégraphiques en France: outils, méthodes et 
tendances des composantes du niveau de la mer au port de Brest ».Version 1-16jan2009.

[2]. Beranrd Simon La Marée - La marée océanique et côtière. Editeur Institut océanographique, 2008, 434pp.

[3]. Woodworth P. L., D. L. Blackman (2004). Evidence for systematic changes in extreme high waters since the Mid-1970s. Journal of Climate, vol. 17, nº, pp. 1190-1197

[4]. S. DESMARE, N. WEBER, «Les nouveaux produits de courants de marée et services proposés par le SHOM». XIIIèmes Journées Nationales Génie Côtier Génie Civil. DOI:10.5150/jngcgc.2014.008 .Dunkerque, 2-4 juillet 2014.disponible en ligne : http://www.paralia.fr

[5]. R.creach, Chief of PE RONIM ,Guide Mesures marégraphiques Version : 2.1 disponible sur: http://agora.shom.fr/docQual/2008/GU/GU2008-056

[6]. O. Kursua, A. Kruusingb, M. Pudasb, T. Rahkonen, Piezoelectric bimorph charge mode force sensor Timo Rahkonena, article science direct, 2009

[7]. Sensor One AE-801 Micro Force Sensor, http://sensorone.com/AE801 Home.

[8]. P.Poulichet Etude des capteurs magnétiques (www.incertitudes.fr/robot/capteurs-magnetique.pdf).

[9]. D.Cordier- Cours de physique, électromagnétisme, 1.Electrostatique et magnétostatique - Editions Dunod.22 juillet 2004.

[10]. National Semiconductor, Application note 31: Op amp circuit collection,http://www.national.com/an/AN/AN31.pdf, September, 2002.

[11]. A.NAKHELI, Thèse de Doctorat Surfusion, Cristallisation et vitrification des Systèmes eaupropanediol 1, 2 à basse température N0: 279-92, 1992, pages: 11-60.

[12]. WO2013105840 A1 Densimeter, PCT/MA2012/000015 Abdelrhani Nakheli \& Seddik Bri.

[13]. J.-L. Le Goer, J. Avril, Capteurs à jauge extensométrique, Techniques de l'ingénieur, pp. 01, 2000 